\title{
PENGARUH PERSPEKTIF PEMBELAJARAN DAN PERTUMBUHAN TERHADAP KINERJA PERSPEKTIF PELANGGAN PADA PASIEN RAWAT JALAN INSTALASI FARMASI RUMAH SAKIT
}

\author{
Muh. Syahruddin \\ Fakultas Farmasi, Universitas Pancasila Jakarta, Indonesia \\ E-mail : muhammadsyahruddin.apt@gmail.com
}

\begin{abstract}
ABSTRAK
Tuntutan kualitas menjadi prioritas di Indonesia khususnya dalam pelayanan di rumah sakit terutama di kota besar. Rumah sakit tidak cukup bila hanya menawarkan pelayanan dengan konsep asal "selamat" tetapi perlu menawarkan hasil maksimal berupa pelayanan yang berdasarkan kepuasan dengan standar profesi yang tinggi. Rumah sakit tidak hanya berfungsi untuk kegiatan mengobati, tetapi merupakan tempat untuk meningkatkan status kesehatan individu, sehingga kualitas kesehatan dan hidup manusia Indonesia meningkat pula. Maka dari itu penulis melakukan penelitian tentang Pengaruh Perspektif Pembelajaran Pertumbuhan Terhadap Kinerja Perspektif Pelanggan pada Instalasi Farmasi Rawat Jalan Rumah Sakit H.M. Djafar Harun Kabupaten Kolaka Utara Sulawesi Tenggara. Metode penelitian yang digunakan adalah studi kasus non eksperimental dengan pendekatan deskriptif serta data diperoleh secara retrospektif dan prospektif, kriteria data yang diperoleh adalah data kualitatif dan kuantitatif. Teknik pengumpulan data yang digunakan yaitudata kualitatif diperoleh dari wawancara mendalam kepada Apoteker Kepala Instalasi Farmasi Rumah Sakit dan karyawan Instalasi Farmasi, observasi langsung, survei terhadap arsip dan dokumen, sedangkan data kuantitatif diperoleh dari kuisioner yang di sebarkan oleh peneliti yaitu kuisioner kepuasan karyawan, semangat kerja karyawan. Hasil Penelitian menunjukkan bahwa kinerja perspektif pembelajaran dan pertumbuhan yaitu karyawan yang mengikuti pelatihan pada tahun 2012 sebanyak 2 orang dan tahun 2013 tidak ada, kepuasan kerja karyawan dengan menggunakan kuisioner dinilai baik, semangat kerja karyawan dengan menggunakan kuisioner dinilai baik / semangat dengan presentase 83,45\%, pengembangan Sistem Informasi Manajemen (SIM) masih secara manual.
\end{abstract}

Kata kunci: Kinerja, Pembelajaran dan Pertumbuhan, Balanced Scorecard. 


\begin{abstract}
The aim of this study is to know how the impact of learning-growth perspective and internal business process perspective to performance customer perspectiveof pharmacy installation for outpatients in BLUD H.M. DjafarHarun Hospital, North Kolaka Region, Southeast Sulawesi. The methodof this study is descriptive, non-experimental case study. The datawas collected with retrospective and prospectivemethodconsist of quantitative and qualitative data. Data was taken from interview with a pharmacist, direct observation, documents survey and questioners to analyze Results of the study are two employees involved in development training in year 2012, no training in 2013, based on questioner employee satisfaction was good, work spirit was also good with percentage $83,45 \%$, management information system needs further development. Based on questioner internal business process is good, level of drug stock availability in year 2012 was 99,12\% and in 2013 was 95,14\%, dispensing time for powder medicine was 13,65 minutes, dispensing time for ready stock medicine was 3,53 minutes, supplier performance has not been good enough, level of medication error and potential error was low. Based on questioner, customer satisfaction was still low, reliability dimension was 0,02, responsiveness 0,00 , tangible 0,00 , assurance 0,01 , empathy $0,02.89,36 \%$ patients in 2012 was covered with pharmaceuticalservice from hospital pharmacy installation, this level decreased in 2013 for 37,20\%, average time for drug information was 25,56 seconds.
\end{abstract}

Keywords: Learning and Growth Perspective, Internal Business Process Perspective, Customer Perspective, Performance, Pharmacy Installation, Public sector,

\section{PENDAHULUAN}

Rumah sakit umum daerah merupakan instansi dibawah naungan pemerintah daerah yang bergerak di bidang sektor publik dengan memberikan pelayanan jasa kesehatan. Pelayanan kesehatan yang diberikan oleh rumah sakit umum daerah bersifat sosial dan ekonomi dengan lebih mengutamakan pelayanan kesehatan yang terbaik bagi masyarakat. Rumah sakit umum daerah sebagai salah satu instansi pemerintah harus mampu memberikan pertanggungjawaban baik secara finansial maupun non finansial kepada pemerintah daerah dan masyarakat sebagai pengguna jasa [1].

Meningkatnya kesadaran masyarakat terhadap penyelenggaraan administrasi publik memicu timbulnya gejolak yang berakar pada ketidakpuasan. Tuntutan yang semakin tinggi diajukan terhadap pertanggung jawaban yang diberikan oleh penyelenggara negara atas kepercayaan yang diamanatkan kepada mereka. Dengan kata lain, kinerja instansi pemerintah kini lebih banyak mendapat sorotan, karena masyarakat mulai mempertanyakan manfaat yang mereka peroleh atas pelayanan instansi pemerintah [2].

Kondisi ini mendorong peningkatan kebutuhan adanya suatu pengukuran kinerja terhadap para penyelenggara negara yang telah menerima amanat dari rakyat. Pengukuran tersebut akan melihat seberapa jauh kinerja yang telah dihasilkan 
dalam suatu periode tertentu dibandingkan dengan yang telah direncanakan [2].

Instalasi farmasi rumah sakit adalah suatu bagian/unit/divisi atau fasilitas di rumah sakit, tempat penyelenggaraan semua kegiatan pekerjaan kefarmasian yang ditujukan untuk keperluan rumah sakit itu sendiri. Seperti diketahui, pekerjaan kefarmasian adalah pembuatan, termasuk pengendalian mutu sediaan farmasi, pengamanan pengadaan, penyimpanan dan distribusi obat, pengelolaan obat, pelayanan obat atas resep dokter, pelayanan informasi obat, serta pengembangan obat, bahan obat dan obat tradisional [3].

Instalasi Farmasi Rumah Sakit yang dijelaskan dalam undang-undang nomor 44 tahun 2009 tentang Rumah Sakit yaitu kefarmasian harus menjamin ketersediaan sediaan farmasi dan alat kesehatan yang bermutu, bermanfaat, aman dan terjangkau, Pelayanan sediaan farmasi di Rumah Sakit harus mengikuti standar pelayanan kefarmasian, Pengelolaan alat kesehatan, sediaan farmasi, dan bahan habis pakai di Rumah Sakit harus dilakukan oleh Instalasi farmasi sistem satu pintu, Besaran harga perbekalan farmasi pada instalasi farmasi Rumah Sakit harus wajar dan berpatokan kepada harga patokan yang ditetapkan Pemerintah [4]

Artikel ini membahas tentang kinerja Instalasi Farmasi Rumah Sakit dengan pendekatan balanced scorecard pada Perspektif Pembelajaran dan Pertumbuhan dikarenakan Instalasi Farmasi yang merupakan aset rumah sakit yang berpengaruh besar terhadap pendapatan rumah sakit, dan pelayanan Instalasi Farmasi yang lebih dekat kepada masyarakat, karena berinteraksi langsung kepada pasien, terutama dalam hal pelayanan obat, sehingga diperlukan evaluasi terhadap kinerjanya. Oleh karena itu, pengaruh perspketif pembelajaran dan pertumbuhan, yang mengacu pada konsep Balanced Scorecard ini bisa digunakan sebagai terobosan cerdas dan inovatif yang membantu rumah sakit khususnya Instalasi Farmasi BLUD Rumah Sakit H.M. Djafar Harun Kabupaten Kolaka Utara Sulawesi Tenggara untuk dapat unggul dan kreatif dalam meningkatkan kinerja manajemen.

Berdasarkan survei awal yang telah dilakukan pada Instalasi Farmasi BLUD Rumah Sakit H.M. Djafar Harun Kabupaten Kolaka Utara Sulawesi Tenggara terdapat permasalahan dalam halsystem inventoryobat, yaitu terjadi kekosongan beberapa item obat yang banyak dipakai, sedangkan disisi lain terjadi kelebihan stok obat yang jarang dipakai, dan pelayanan farmasi yang tidak satu pintu, akibatnya akan berdampak pada kepuasan pelanggan dalam hal ini Instalasi Farmasi BLUD Rumah Sakit H.M. Djafar Harun Kabupaten Kolaka Utara Sulawesi 
Tenggara, karena Instalasi Farmasi BLUD Rumah Sakit H.M. Djafar Harun Kabupaten Kolaka Utara Sulawesi Tenggara tidak dapat melayani item obat yang kosong yang dibutuhkan oleh masyarakat. Hal ini disebabkan karena selama ini, Formularium rumah sakit bel um diterapkan dengan baik, pengadaan perbekalan farmasi yang ada masih mengacu pada Formularium Nasional dan atas permintaan dokter. sehingga visi Rumah Sakit rujukan yang berkualitas dan terjangkau belum bisa tercapai

Berdasarkan hal tersebut di atas, maka dirasa peneliti perlu melakukan penelitian Pengaruh Perspektif Pembelajaran dan Pertumbuhan terhadap kinerja Perspektif Pelanggan pada Instalasi Farmasi Rawat Jalan BLUD Rumah Sakit H.M. Djafar Harun Kabupaten Kolaka Utara Sulawesi Tenggara.

\section{METODE PENELITIAN}

Metode yang digunakan dalam penelitian ini adalah studi kasus non eksperimental dengan pendekatan deskriptif. Penelitian ini dimaksudkan untuk mengetahui kinerja Instalasi Farmasi BLUD Rumah Sakit H.M. Djafar Harun Kabupaten Kolaka Utara Sulawesi Tenggara yang ditinjau dari perspektif pembelajaran dan pertumbuhan terhadap perspektif pelanggan dengan pendekatan Balanced Scorecard. Data diperoleh secara retrospektif dan prospektif, kriteria data yang diperoleh adalah data kualitatif dan kuantitatif. Data kualitatif diperoleh berdasarkan kuisioner dengan skala likert yang diisi secara langsung oleh responden, wawancara mendalam dengan apoteker dan staf Instalasi Farmasi Rawat Jalan BLUD Rumah Sakit H.M. Djafar Harun Kabupaten Kolaka Utara Sulawesi Tenggara. Data kuantitatif diperoleh berdasarkan observasi langsung, survei terhadap resep yang terlayani di Instalasi Farmasi Rawat Jalan BLUD Rumah Sakit H.M. Djafar Harun Kabupaten Kolaka Utara Sulawesi Tenggara.

Populasi dan Responden pada penlitian ini yaitu seluruh karyawan Instalasi Farmasi BLUD Rumah Sakit H.M. Djafar Harun Kabupaten Kolaka Utara Sulawesi Tenggara sebanyak 15 responden, pasien atau keluarga pasien yang berkunjung di Instalasi Farmasi Rawat Jalan BLUD H.M. Djafar Harun Kabupaten Kolaka Utara untuk menebus obat sebanyak 184 responden, jadi jumlah responden yang digunakan sebanyak 199 responden, penentuan jumlah responden ini berdasarkan tabel yang dikembangkan oleh Isaac dan Michael untuk jumlah populasi 750 per bulan dengan tingkat kesalahan $10 \%$ (19).Penentuan responden pada penelitian ini yaitu seluruh karyawan Instalasi Farmasi BLUD H.M. Djafar Harun Kabupaten Kolaka Utara karena seluruh karyawan tersebut bertanggung jawab dalam pelayanan kefarmasian yang ada di 
Rumah Sakit, serta pasien atau keluarga pasien yang berkunjung di Instalasi Farmasi Rawat Jalan BLUD Rumah Sakit H.M. Djafar Harun Kabupaten Kolaka Utara untuk menebus obat karena pasien atau keluarga pasien tersebut dapat memberikan respon terhadap kepuasan pelanggan

terhadap

pelayanan

kefarmasian yang diberikan oleh karyawan Intalasi Farmasi Rumah Sakit.

\section{HASIL DAN PEMBAHASAN}

Karakteritik responden karyawan Instalasi Farmasi.

Tabel 1. Karakteritik Responden Karyawan Instalasi Farmasi berdasarkan umur.

\begin{tabular}{|c|c|}
\hline Karakteristik Umur & Persentase \\
\hline$<30$ & $73,33 \%$ \\
\hline $31-40$ & $26,66 \%$ \\
\hline$>40$ & - \\
\hline $\begin{array}{l}\text { Dari tabel diatas, dapat dilihat } \\
\text { bahwa responden karyawan IFRS } \\
\text { berdasarkan umur yaitu umur < } 30 \\
\text { tahun sebanyak } 11 \text { orang dengan } \\
\text { persentase } 73,33 \% \text {, umur } 31-40\end{array}$ & $\begin{array}{l}\text { persentase } 26,66 \% \text {, dan umur }>40 \\
\text { tahun tidak ada, dapat disimpulkan } \\
\text { bahwa karyawan IFRS rata-rata memiliki } \\
\text { umur yang masih produktif di dalam } \\
\text { bekerja untuk meningkatkan kualitas } \\
\text { pelayanan. }\end{array}$ \\
\hline
\end{tabular}

Tabel 2. Karakteritik Responden Karyawan Instalasi Farmasi berdasarkan Jenis Kelamin.

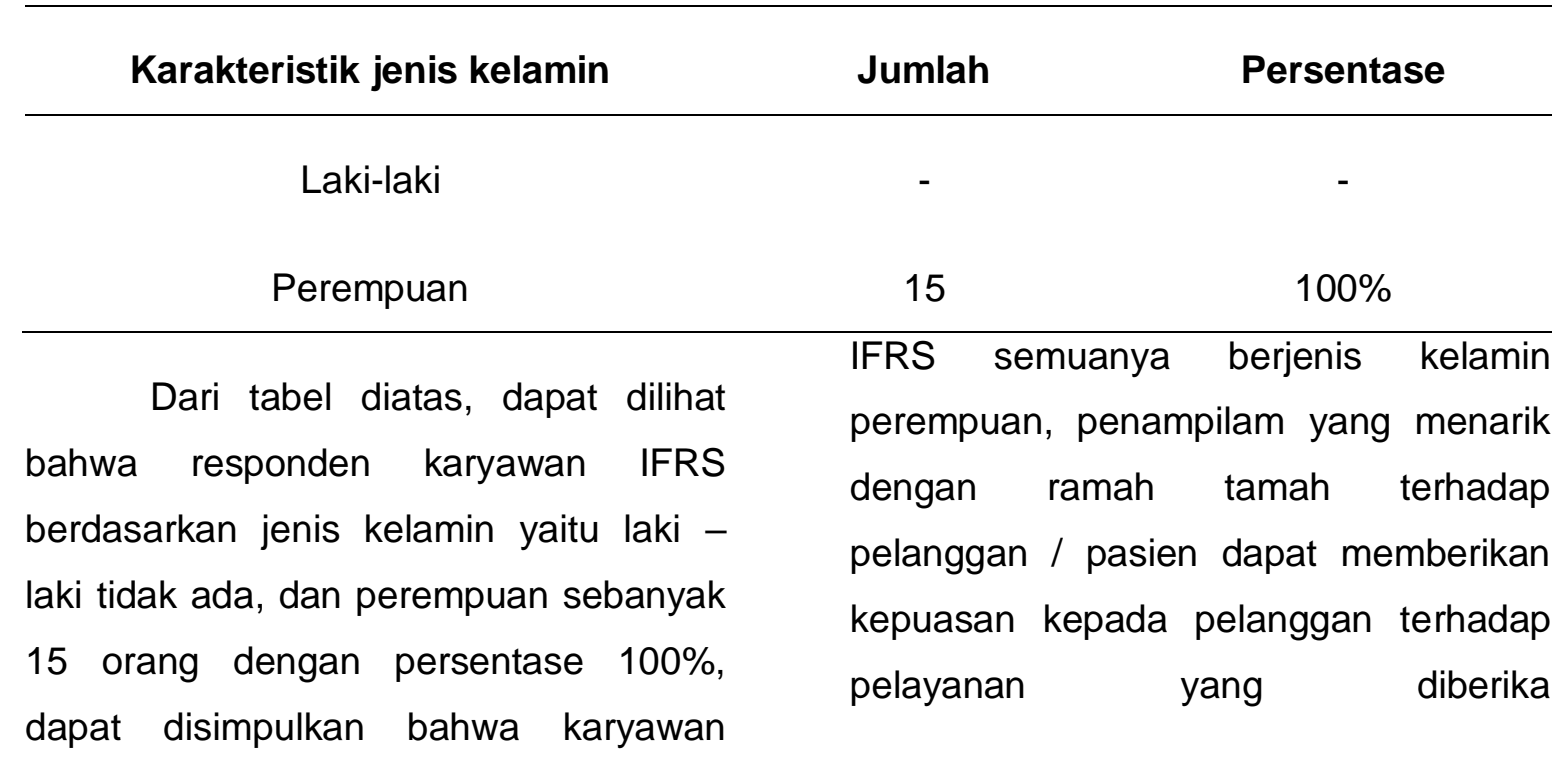


Tebel 3. Tabel Karakteritik Responden Karyawan Instalasi Farmasi berdasarkan Pendidikan

\begin{tabular}{|c|c|}
\hline Karakteristik Pendidikan & Persentase \\
\hline SMA/SMF & $13,33 \%$ \\
\hline S1 & $20 \%$ \\
\hline Profesi Apoteker & $66,66 \%$ \\
\hline $\mathrm{S} 2$ & - \\
\hline $\begin{array}{l}\text { Dari tabel diatas, dapat dilihat } \\
\text { bahwa responden karyawan IFRS } \\
\text { berdasarkan pendidikan yaitu } \\
\text { pendidikan SMA/SMF sebanyak } 2 \text { orang } \\
\text { dengan persentase } 13,33 \% \text {, Pendidkan } \\
\text { Sarjana (S1) sebanyak } 3 \text { orang dengan } \\
\text { persentase } 20 \% \text {, yang berpendidikan } \\
\text { Profesi (Apoteker) sebanyak } 10 \text { orang } \\
\text { dengan persentase } 66,66 \% \text { Dan }\end{array}$ & $\begin{array}{l}\text { disimpulkan bahwa mayoritas karyawan } \\
\text { IFRS berpendidikan Profesi Apoteker, } \\
\text { dalam hal ini karyawan IFRS dianggap } \\
\text { mampu dan baik dalam memberikan } \\
\text { pelayanan kepada pelanggan/pasien, } \\
\text { dengan pendidikan yang tinggi dan } \\
\text { kemampuan yang baik dalam } \\
\text { menjalankan tugas dan tanggung jawab } \\
\text { kerja dapat meningkatkan kualitas dalam } \\
\text { pekerjaan. }\end{array}$ \\
\hline
\end{tabular}
pendidikan S2 tidak ada. Dapat

Tabel 4. Karakteritik Responden Karyawan Instalasi Farmasi berdasarkan Masa Kerja

\begin{tabular}{|c|c|}
\hline Karakteristik Masa Kerja & Persentase \\
\hline $1-5$ & $40 \%$ \\
\hline $6-10$ & $60 \%$ \\
\hline$>10$ & - \\
\hline $\begin{array}{l}\text { Dari tabel diatas, dapat dilihat } \\
\text { bahwa responden karyawan IFRS } \\
\text { berdasarkan masa kerja yaitu masa kerja } \\
1-5 \text { tahun sebanyak } 6 \text { orang dengan } \\
\text { persentase } 40 \% \text {, masa kerja } 6-10\end{array}$ & $\begin{array}{l}\text { tahun sebanyak } 9 \text { orang dengan } \\
\text { persentase } 60 \% \text {, dan masa kerja }>10 \\
\text { tahun tidak ada, dengan hasil tersebut } \\
\text { dapat disimpulkan bahwa mayoritas } \\
\text { karyawan IFRS memiliki masa kerja } 6-\end{array}$ \\
\hline
\end{tabular}


10 tahun sebanyak $60 \%$, ini menunjukkan bahwa karyawan IFRS sudah memiliki banyak pengetahuan dan pengalaman dalam bidang pelayanan kefarmasian kepada pelanggan/pasien.

Perspektif Pembelajaran dan pertumbuhan merupakan suatu hal yang penting untuk diukur agar mampu mendorong Instalasi Farmasi BLUD Rumah Sakit H.M. Djafar Harun menjadi Learning organisation yang merupakan organisasi yang terus menerus melakukan peningkatan kapasitasnya untuk mendorong pertumbuhannya yang lebih baik. Adapun indikator yang di ukur yakni:

Persentase pelatihan karyawan, Upaya Instalasi Farmasi BLUD Rumah Sakit H.M. Djafar Harun untuk meningkatkan pengetahuan dan kompetensi personelnya antara lain dengan mengikut sertakan pelatihan para petugas IFRS, diharapkan dengan mengikuti pelatihan keterampilan, pengalaman dan kompetensi petugas meningkat sehingga proses pelayanan kefarmasian kepada pasien akan semakin meningkat.

Tabel 5. Persentase karyawan yang mendapat pelatihan tahun 2012 - 2013.

\begin{tabular}{|c|c|}
\hline \multirow[t]{2}{*}{ Keterangan } & Tahun \\
\hline & 2012 \\
\hline Jumlah Karyawan & 15 \\
\hline Karyawan yang mendapatkan pelatihan & 0 \\
\hline Persentase karyawan yang mendapat pelatihar & $13,33 \%$ \\
\hline $\begin{array}{l}\text { Sumber: Data primer yang diolah } \\
\text { Karyawan Instalasi Farmasi } \\
\text { sebagai salah satu motor penggerak } \\
\text { rumah sakit yang berada digaris depan } \\
\text { dalam memberikan pelayanan kepada } \\
\text { pasien sudah seharusnya menjadi } \\
\text { pelatihan terkait dengan peningkatan } \\
\text { kapabilitas dan kompetensinya sehingga } \\
\text { dapat berkontribusi positif terhadap } \\
\text { rumah sakit. Hasil penelitian persentase } \\
\text { karyawan yang mengikuti pelatihan pada }\end{array}$ & $\begin{array}{l}\text { tahun } 2012 \text { hanya } 2 \text { karyawan yang } \\
\text { mengikuti pelatihan yaitu pelatihan } \\
\text { Pelayanan Informasi Obat pada bulan } \\
\text { Juni } 2012 \text { dan pelatihan Formularium } \\
\text { Rumah Sakit pada bulan Agustus } 2012 \\
\text { dengan peresentase } 13,33 \% \text {. Dan pada } \\
\text { tahun } 2013 \text { karyawan IFRS tidak pernah } \\
\text { mengikuti pelatihan, dan berdasarkan } \\
\text { hasil kuisioner yang disebar kepada } \\
\text { karyawan IFRS sebagian besar }\end{array}$ \\
\hline
\end{tabular}


karyawan pernah mengikuti seminar Kefarmasian/Kesehatan.

Persentase Kepuasan karyawan Hasil kepuasan karyawan terhadap 7 indikator pertanyaan dapat dilihat pada tabel berikut :

Tabel 6. Persentase Tingkat Kepuasan Karyawan Instalasi Farmasi BLUD Rumah Sakit H.M. Djafar Harun.

\begin{tabular}{lcccc}
\hline \multicolumn{1}{c}{ Keterangan } & $\begin{array}{c}\text { Sangat } \\
\text { Puas (\%) }\end{array}$ & Puas (\%) & $\begin{array}{c}\text { Tidak Puas } \\
(\%)\end{array}$ & $\begin{array}{c}\text { Sangat } \\
\text { Tidak } \\
\text { Puas (\%) }\end{array}$ \\
\hline Uang Jasa & 6,66 & 86,66 & 6,66 & - \\
Pekerjaan & 6,66 & 93,33 & - & - \\
Pengawasan & 6,66 & 93,33 & - & - \\
Hubungan dengan Ka. IFRS & 6,66 & 93,33 & - & - \\
Promosi Jabatan & 13,32 & 80,00 & 6,66 & - \\
Jam Kerja & 6,66 & 93,33 & - & - \\
Tugas Kerja & 6,66 & 93,33 & $\mathbf{1 , 9 0}$ & - \\
Rata-rata & $\mathbf{7 , 6 1}$ & $\mathbf{9 0 , 4 7}$ & & \\
\hline
\end{tabular}

Sumber : data primer yang diolah

Berdasarkan hasil tabel diatas, dapat diterangkan sebagai berikut, dari segi uang jasa yang diterima, sebanyak $6,66 \%$ responden yang merasa sangat puas terhadap uang jasa yang mereka terima, sebanyak $86,66 \%$ responden merasa puas terhadap uang jasa yang mereka terima, dan 6,66\% responden yang merasa tidak puas. Pada aspek kepuasan pada pekerjaan sebanyak $6,66 \%$ responden menyatakan sangat puas dengan pekerjaannya, 93,33\% merasa puas. Pendapat responden terhadap kepuasan pada pengawasan selama kerja adalah $6,66 \%$ merasa sangat puas, dan 93,33\% merasa puas. Kepuasan pada hubungan dengan Kepala Instansi Farmasi yaitu, 6,66\% yang menyatakan sangat puas, dan 93,33\% menyatakan puas.Kepuasan responden terhadap promosi jabatan yaitu13,32\% responden menyatakan sangat puas, $80,00 \%$, $6,66 \%$ menyatakan tidak puas. Kepuasan pada 
jam kerja yaitu $6,66 \%$ menyatakan sangat puas dan $93,33 \%$ menyatakan puas. Kepuasan responden terhadap pembagian tugas kerja yaitu $6,66 \%$ merasa sangat puas, $93,33 \%$ menyatakan puas.

Semangat Kerja Karyawan, Pada Indikator ini dilakukan pengamatan terhadap karyawan IFRS yang memenuhi syarat sebagai responden yaitu masa kerja minimal satu tahun dan di dapatkan 15 responden / karyawan IFRS, pengukuran semangat kerja karyawan ini diukur dengan menggunakan kuisioner yang terdapat pada lampiran dari pengisian kuisioner tersebut diharapkan dapat diketahui sejauh mana semangat kerja karyawan di Intalasi Farmasi BLUD Rumah Sakit H.M. Djafar Harun Kolaka Utara, dengan harap dapat meningkatkan kinerja dan kualitas pelaynan serta meningktakan kepuasan pasein. Hasil persentase skala semnagt kerja karywan dapat dilihat pada tabel berikut :

Tabel7. Persentase semangat kerja karyawan Instalasi Farmasi BLUD H.M. Djafar Harun.

\begin{tabular}{|c|c|c|c|c|}
\hline \multirow[b]{2}{*}{ No. } & \multirow[b]{2}{*}{ Pertanyaan } & \multicolumn{3}{|c|}{ Keterangan } \\
\hline & & $\begin{array}{c}\text { Total } \\
\text { Jawaban }\end{array}$ & $\begin{array}{l}\text { Rata- } \\
\text { Rata }\end{array}$ & $\begin{array}{c}\text { Persentase } \\
(\%)\end{array}$ \\
\hline 1 & $\begin{array}{l}\text { Saya berangkat kerja dengan hati } \\
\text { yang mantap }\end{array}$ & 51 & 3,40 & 85,00 \\
\hline 2 & $\begin{array}{l}\text { Saya memikirkan cara agar hasil } \\
\text { kerja saya menjadi lebih baik. }\end{array}$ & 51 & 3,40 & 85,00 \\
\hline 3 & $\begin{array}{l}\text { Ada rasa puas dalam hati bila } \\
\text { pekerjaan saya selesai tepat pada } \\
\text { waktunya }\end{array}$ & 55 & 3,66 & 91,50 \\
\hline 4 & $\begin{array}{l}\text { Saya menyenangi pekerjaan saya } \\
\text { di sini }\end{array}$ & 50 & 3,33 & 83,25 \\
\hline 5 & $\begin{array}{l}\text { Saya percaya bahwa rekan kerja } \\
\text { memahami saya }\end{array}$ & 48 & 3,20 & 80,00 \\
\hline 6 & $\begin{array}{l}\text { Saya merasa seakan-akan } \\
\text { pekerjaan saya di sini merupakan } \\
\text { bagian dari hidup saya }\end{array}$ & 50 & 3,33 & 83,25 \\
\hline 7 & $\begin{array}{l}\text { Saya merasa bahwa saya } \\
\text { menghayati pekerjaan saya }\end{array}$ & 44 & 2,93 & 73,25 \\
\hline 8 & Saya berusaha datang ke tempat & & & \\
\hline
\end{tabular}




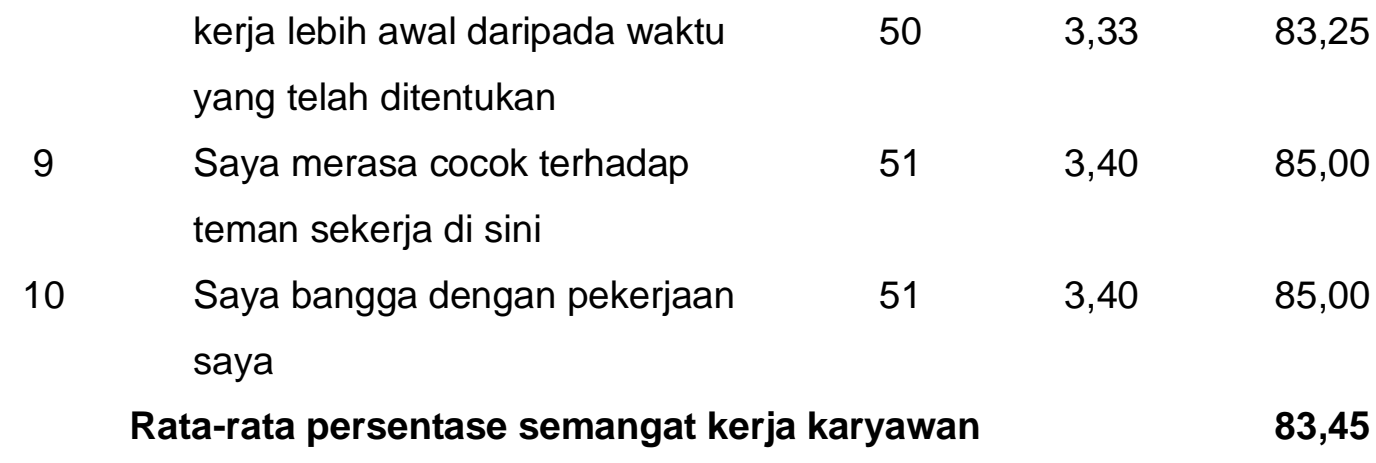

Sumber : Data primer yang diolah

Dari hasil pengolaha data diatas, dapat diketahui bahwa semangat kerja karyawan Intalasi Farmasi BLUD H.M. Djafar Harun Kabupaten Kolaka Utara Sulawesi Tenggara sangat tinggi, hal ini dibuktikan dengan hasil pengolahan data di dapatkan persentase rata-rata semangat kerja karyawan IFRS yaitu $83,45 \%$. Hal ini harus terus ditingkatkan dan harus selalu memperhatikan farktor-faktor yang mempengaruhi semangat kerja tersebut, agar semua pelayanan kepada pasien dapat berjalan dengan baik sesuai dengan harapan pasein, dengan semangat kerja yang tinggi akan menhasilkan pelayanan yang baik pula.

Pengembangan Sistem Informasi manajemn (SIM), Pada indikator pengembangan Sistem Informasi manajemen (SIM) yang ada Instalasi Farmasi BLUD Rumah Sakit H.M. Djafar Harun masih manual, Berdasarkan hasil wawancara dengan Kepala Instalasi Farmasi bahwa ada keinginan untuk mengembangkan SIM khusus di IFRS, tetapi karena keterbatasan, sehingga sampai sekarang masih menggunakan SIM yang manual, Database obat masih diinput dalam bentuk Microsoft Excel, software yang belum ada tetapi masih sementara direncanakan, dan belum terealisasi sampai tahun 2014, kemungkinan akan diusahakan dapat terealisasi di tahun mendatang siring berjalananya perubahan status Rumah Sakit Umum Daerah (RSUD) menjadi Daerah (BLUD).

Berdasarkan hasil penelitian diatas menunjukkan hasil bahwa, persentase pelatihan karyawan yang baik akan menambah pengetahuan dan wawasan karyawan didalam pelayanan dimana akan menghasilkan waktu pelayanan penyiapan obat akan semakin baik dan efektif, dan juga akan menghindari terjadinya medication error dan potential error, karena karyawan sudah cukup mampu, teliti, dan terampil dalam memberikan pelayanan kefarmasian kepada pasien, dan juga di tunjang dengan semangat kerja karyawan yang tinggi akan menambah nilai potsitif terhadap kinerja karyawan. Semangat kerja karyawan dan kepuasan kerja kerja karyawan dapat membantu dalam tingkat 
ketersediaan obat lebih baik, dan pengembangan SIM yang baik atau secara online system akan memepermudah dalam mengontrol stok yang ada di IFRS sehingga stok dan pemasok dapat di kontrol dengan baik.

\section{Kesimpulan}

Berdasarkan hasil penelitian dan pembahasan pada penelitian ini, maka diperoleh kesimpulan bahwa Kinerja Perspektif Pembelajaran dan Pertumbuhan

1. Karyawan Intalasi Farmasi Rawat Jalan BLUD Rumah Sakit H.M. Djafar Harun Kabupaten Kolaka Utara Sulawesi Tenggara yang mengikuti pelatihan pada tahun 2012 sebanyak 2 orang dan tahun 2013 tidak ada yang mengikuti pelatihan, akan tetapi mayoritas karyawan IFRS pernah mengikuti seminar kafarmasian/kesehatan.

2. Kepuasan kerja karyawan dengan menggunakan kuisioner dinilai baik oleh karyawan Intalasi Farmasi BLUD Rumah Sakit H.M. Djafar Harun Kabupaten Kolaka Utara Sulawesi Tenggara.

3. Semangat kerja karyawan dengan menggunakan kuisioner dinilai baik / semangat dengan presentase $83,45 \%$

4. Pengembangan Sistem Informasi Manajemen (SIM) masih secara manual.

\section{Daftar Pustaka}

1. Hafizurrachman., Sumber Daya Manusia Rumah Sakit di Q-Hospital, Fakultas Kesehatan Masyarakat, Universitas Indonesia, Jakarta : 2009 ; 343-344.

2. Mahsun, Mohamad., Pengkuran Kinerja Sektor Pelayanan Publik., BPFE., Yogyakarta; 2013 ; 168 - 173.

3. Siregar, Charles dan Lia Amalia.Farmasi Rumah Sakit Teori dan Penerapan. Jakarta. Penerbit Buku Kedoteran EGC; 2004 ; 24,26,30-34.

4. Peraturan Pemerintah $\mathrm{RI}$ Nomor 51 tahun 2009., Tentang Pelayanan Kefarmasian; Jakarta, 2009 ; 196.

5. Anonim., Rencana Strategi Rumah Sakit Umum Daerah H.M. Djafar Harun Kabupaten Kolaka Utara Sulawesi Tenggara; 2007.

6. Harvey., Analisis Pengembangan Instalasi Farmasi Berbasis Evaluasi Akreditasi Rumah Sakit dengan Metode Hanlon di RSUD H.M. Djafar Harun Kabupaten Kolaka Utara Sulawesi Tenggara., Tesis. Fakultas Farmasi, Surakarta.Universitas Setia Budi; 2013 ; 9-16.

7. Departemen Kesehatan Republik Indonesia, Undang-Undang Republik Indonesia No. 44 tahun 2009 tentang Rumah Sakit. Jakarta ; 2009; 189.

8. Departemen Kesehatan Republik Indonesia, No 
1197/Menkes/SK/X/2004 Tentang

Standar Pelayanan Farmasi di Rumah

Sakit. Direktorat Jenderal Pelayanan

Kefarmasian dan Alat Kesehatan. Jakarta; 2004; 1 -2.

9. Supranto. J, Nandan Limakrisna., Petunjuk Praktis Penelitian IImiah Untuk Menyusun Skripsi, Tesis, dan Disertasi., Jakarta., Mitra Wacana Media; 2012; 94

10. Arikunto, Suharsimi. 2002. Prosedur Penelitian: Suatu Pendekatan Praktek.
Edisi Revisi V. Rineka Cipta. Jakarta ; 154.

11. Santosa, Singgih., Menguasai Statistik di Era Informasi dengan SPSS 15., PT. Elex Media Komputindo, Kelompok Gramedia, Jakarta. 2007; 273.

12. Srimindarti, C., Balanced Scorecard Sebagai Alternatif untuk Mengukur Kinerja, web jurnal, http://www.stiestikubank.ac.id/, (27 November 2013); 2006. 